Mots. Les langages du politique

\title{
Les professions de foi à l'occasion des élections présidentielles françaises
}

The declarations of principles on the occasion of the French presidential elections

Las declaraciones de principios en el caso de las elecciones presidenciales francesas

\section{Marc Bonhomme}

\section{OpenEdition}

\section{Journals}

Édition électronique

URL : https://journals.openedition.org/mots/22417

DOI : $10.4000 /$ mots. 22417

ISSN : 1960-6001

Éditeur

ENS Éditions

\section{Édition imprimée}

Date de publication : 15 octobre 2016

Pagination : 21-22

ISBN : 978-2-84788-850-8

ISSN : 0243-6450

\section{Référence électronique}

Marc Bonhomme, «Les professions de foi à l'occasion des élections présidentielles françaises », Mots. Les langages du politique [En ligne], 112 | 2016, mis en ligne le 15 octobre 2018, consulté le 22 avril 2022. URL : http://journals.openedition.org/mots/22417 ; DOI : https://doi.org/10.4000/mots.22417 


\section{Les professions de foi à l'occasion des élections présidentielles françaises}

Ayant pour but de diffuser à l'adresse des citoyens l'argumentaire des candidats à une élection, les professions de foi constituent un micro-genre politique proche des messages publicitaires ${ }^{1}$. Comme pour la publicité, on a en effet affaire à du discours qui comporte une dimension épidictique (mise en valeur du candidat) et persuasive (incitation à voter pour lui). Les professions de foi électorales ont en outre un statut paradoxal. D'un côté, elles jouent un rôle non négligeable auprès de l'opinion publique. Comme l'indique une enquête de l'Institut CSA effectuée en mars 2012, 62 \% des personnes interrogées estiment qu'elles sont utiles pour faire leur choix au moment d'une élection. Mais d'un autre côté, elles pâtissent d'une désaffection de la part des chercheurs, la plupart des ouvrages consacrés à la communication politique les ignorant ou leur accordant seulement quelques lignes. Cette désaffection s'explique par la relative stéréotypie de ces documents et par leur statut hybride, entre politique et marketing. Les professions de foi ont néanmoins alimenté un certain nombre de travaux qui attestent leur intérêt pour l'étude du débat politique en France lors de la tenue d'élections, notamment présidentielles.

\section{Un micro-genre politique transversal}

Les recherches sur les professions de foi sont hétérogènes du fait que ce microgenre déborde les élections présidentielles pour recouvrir les scrutins les plus variés. Ainsi, Paul Oriol (2000) met en lumière la manière dont l'immigration constitue l'une des préoccupations des professions de foi produites à propos des élections européennes de 1999. Mais ce sont surtout celles que produisent les candidats à l'occasion des élections législatives qui ont retenu l'attention des chercheurs selon deux orientations. Plusieurs études les envisagent dans une perspective historiographique. Yves Déloye (1999) montre que les professions de foi des législatives de 1848 font état d'un double débat touchant la

1. NDLR : le CEVIPOF a mis en ligne ses archives électorales, dont un nombre important de professions de foi : 〈https://archive.org/details/archiveselectoralesducevipof〉(consulté le 31 mai 2016).

Université de Berne

marc.bonhomme@rom.unibe.ch

Mots. Les langages du politique $\mathrm{n}^{\circ} 112$ novembre $2016 \bullet 21$ 
démocratie représentative : celui sur ce qu'est être « un bon représentant » et celui sur les compétences attribuées aux députés. Antoine Prost (1974) fournit un inventaire comparatif et statistique d'envergure sur le vocabulaire des professions de foi parlementaires des années 1881, 1885 et 1889. Cette approche quantitative lui permet de faire ressortir leurs configurations lexicales prédominantes en liaison avec leur contexte politique et l'évolution des mentalités de l'époque. Quant à l'étude de Brigitte Gaïti (1999) sur les législatives de 1958, elle révèle comment les quelques professions de foi qu'elle examine confirment la délégitimation des représentants de la Quatrième République et la promotion de représentants de nouveaux groupes sociaux.

D’autres études adoptent une approche plus thématique sur les professions de foi législatives. Marion Paoletti (2005) analyse le thème de la proximité dans des professions de foi diffusées en Gironde à l'occasion des législatives de 2002. Si, dans celles du premier tour, la proximité est plutôt investie sur un mode civique, avec une revendication au droit à la parole pour tout citoyen, dans celles du second tour, elle est traitée sur un mode domestique qui valorise les interventions concrètes des candidats au sein de leur circonscription. Pour leur part, Aurélie Morin et Cécile Sourd (2007) se penchent sur les professions de foi des législatives de 2002 et des cantonales de 2004 dans le Rhône, en évaluant l'usage élastique qu'elles font du terme « démocratie » suivant les courants politiques des candidats. D'autres travaux sur les professions de foi concernent la représentation du genre féminin lors d'élections législatives, comme ceux de Sandrine Lévêque (2005) et de Magali Guaresi (2014).

\section{Les professions de foi présidentielles comme discours d'autopromotion}

Lorsqu'elles se concentrent sur les élections présidentielles, les recherches sur les professions de foi présentent quelques inflexions par rapport aux travaux précédents. Elles entrent peu dans une perspective historiographique en raison du caractère récent de ce type d'élections au suffrage universel en France. Elles ont une prédilection pour la présidentielle de 2002, ce qui peut s'expliquer par l'importance de son enjeu, du fait de la présence du candidat d'extrême-droite au second tour. Enfin, elles adoptent majoritairement la méthodologie de l'analyse du discours appliquée à leurs trois grandes dimensions.

\section{Mise en scène des candidats}

Les professions de foi pour les élections présidentielles développent prioritairement un discours dans lequel les candidats mettent en exergue leurs qualités en vue de la magistrature suprême. Cette mise en valeur tient à certains 
dispositifs rédactionnels analysés par Emmanuelle Cambon (2005) comme, en 2002, la citation par le candidat Jean-Marie Le Pen de propos approuvant son action : «Le Pen a raison», «Le Pen dit tout haut ce que tout le monde pense tout bas »... Un tel procédé permet au candidat de faire son propre éloge à travers l'appréciation du public et de le rendre plus objectif. En cela, il renforce son ascendant susceptible d'entraîner un effet de ralliement.

D'autres recherches se placent dans un cadre rhétorique pour dégager l'ethos des candidats, à savoir l'image qu'ils construisent d'eux-mêmes par leur discours. Ainsi, l'ouvrage d'Ali Alsafar (2015) est entièrement consacré à l'élaboration langagière de l'ethos des candidats dans les professions de foi des présidentielles de 2007 et de 2012. La construction de leur image s'effectue principalement au moyen des slogans, des marques de personne, des motsphares et des modalités énonciatives. De la sorte, en 2012, Jean-Luc Mélenchon affiche un ethos de solidarité, visible dans son slogan («Prenez le pouvoir»), ses effacements énonciatifs (infinitifs, phrases nominales...) et son recours récurrent au nous inclusif. A. Alsafar souligne de surcroît les transformations des ethos construits par un même candidat entre 2007 et 2012. Par exemple, les slogans de Nicolas Sarkozy évoluent entre l'instauration d'un ethos de communion («Ensemble tout devient possible») et celle d'un ethos de chef ("La France forte »). De plus, A. Alsafar établit une corrélation entre les ethos des candidats et leur parti politique. Les candidats du Front national (Jean-Marie Le Pen et Marine Le Pen) arborent un ethos de caractère, fondé sur la critique de leurs adversaires, tandis que les candidats écologiques manifestent un ethos de vertu, basé sur un discours de vérité.

La construction d'un ethos positif par les candidats à l'élection présidentielle exploite aussi les ressources de l'image, comme le montre l'étude de Hugues Constantin de Chanay (2006) sur leurs portraits figurant dans leurs professions de foi de 2002. Par-delà leur apparence naturelle, ceux-ci comportent en filigrane deux sortes de marqueurs de valorisation. D'abord, des marqueurs plastiques concrétisés par la taille, l'emplacement ou l'échelle de ces portraits. Ainsi, le portrait assez réduit de Lionel Jospin suscite un effet de discrétion qui annonce un ethos de modestie. Le portrait de François Bayrou en très gros plan produit un effet de relation intime entre le candidat et le public. À ces marqueurs plastiques s'ajoutent des marqueurs iconiques de contenu qui confortent la valorisation des candidats. Entre autres, le choix de certains vêtements (Olivier Besancenot en chemise) connote une volonté de décontraction et de simplicité. La comparaison des portraits du premier et du second tour fait voir des réajustements d'ethos. Pour Jacques Chirac, ceuxci vont dans le sens du renforcement, avec une augmentation de la taille de l'image et un estompage du décor qui crée un gain en officialité dans la profession de foi du second tour. Pour Jean-Marie Le Pen, le réajustement entre les deux tours se traduit par un véritable repositionnement, avec le passage d'un 
ethos contestataire (absence de sourire, gros plan intrusif...) à un ethos fédérateur (sourire, arrière-plan lumineux...).

\section{Positionnement politique des messages électoraux}

D’autres études portent sur le contenu lexical des professions de foi pour en élucider les orientations politiques. S'intéressant à la profession de foi de Noël Mamère lors de la présidentielle de 2002, Élodie Raulet (2004) la soumet à un traitement informatique afin d'en discerner le positionnement idéologique et la force d'engagement. Les noms les plus fréquents dans sa profession de foi le situent parmi les "activistes identitaires », en ce qu'il développe un programme de gauche plus sociétal que celui du Parti socialiste. En même temps, les verbes prédominants dans sa profession de foi témoignent d'un discours volontariste, centré sur l'implication citoyenne. S'attachant également aux verbes dans les professions de foi du premier tour de la présidentielle de 2002, Jean-Michel Rampon (2006) en effectue une analyse lexicométrique selon une autre optique : celle d'identifier les lignes de partage entre les seize candidats en lice. L'examen des infinitifs lui permet de mettre au jour plusieurs tendances. Si les deux candidats d'extrême-droite privilégient les infinitifs préfixés en re- («redonner», "rétablir», etc.), les candidats de droite ont une préférence pour ceux de type faire, tandis que les candidats de gauche se polarisent au contraire sur ceux qui marquent une abolition. Étendant son analyse à l'ensemble des formes verbales des professions de foi, J.-M. Rampon explicite les orientations lexicales des candidats. En particulier, quand les verbes de garantie sont saillants chez Lionel Jospin, les verbes exprimant le savoir sont symptomatiques chez Jean-Pierre Chevènement qui se présente en homme le plus qualifié au regard de la situation politique.

Certains travaux sont plus spécifiquement axés sur les procédés argumentatifs déployés dans les professions de foi. S'appuyant sur la linguistique systémique, David Banks (2005) effectue une analyse fonctionnelle de la profession de foi de Jean-Marie Le Pen pour le second tour de la présidentielle de 2002. Il y relève une convergence de procédés (nominalisations, utilisations adjectivales des participes, etc.) à travers lesquels le candidat transmet au lecteur un contenu politique qu'il est censé accepter comme présupposé. Cette profession de foi multiplie en outre les phrases négatives indiquant un discours de résistance. Prenant aussi pour objet les professions de foi du second tour de la présidentielle de 2002, Lamria Chetouani (2005) éclaircit le recours à la comparaison chez Jean-Marie Le Pen et Jacques Chirac. À travers elle, les deux candidats s'assimilent à de grandes valeurs symboliques, la nation pour le premier et la France pour le second. À l'inverse, en employant des comparaisons différenciantes, ils confrontent avantageusement leur ligne politique avec les positions adverses. Cet emploi se traduit chez Jean-Marie Le Pen par l'apologie d'un 
passé rayonnant à l'encontre de la dégradation présente de la France, alors que Jacques Chirac revendique un futur meilleur, critiquant le bilan gouvernemental de la gauche sortante et les risques d'aventurisme de son concurrent direct.

\section{Dispositif communicationnel des professions de foi}

Quelques études explorent la dynamique communicationnelle des professions de foi dans leur sollicitation de l'opinion publique. Comme le remarque Ghislaine Lozachmeur (2005) à propos de la présidentielle de 2002, elles mettent en jeu un locuteur-candidat omniprésent qui endosse plusieurs rôles : acteur assumant ses propos, porte-parole de son parti politique (cas de Lionel Jospin) ou témoin rapportant des faits extérieurs... Elles comportent aussi une fonction directive marquée, alternant entre des impératifs et des formulations prescriptives plus impersonnelles («il faut», «il s'agit de », caractéristiques chez Arlette Laguiller et Jacques Chirac...) qui donnent une valeur d'évidence au message politique communiqué. L'interactivité de ces professions de foi présidentielles de 2002 est plus systématiquement analysée par Marc Bonhomme (2004) avec les apports de la linguistique conversationnelle. D'une part, il en relève le monologisme constitutif, les candidats occupant massivement le champ de la parole avec une communication autocentrée et une argumentation bouclée qui trouve en elle-même ses justifications (ainsi chez Alain Madelin). D'autre part, ces professions de foi sont sous-tendues par un important cadrage dialogique, en ce qu'elles instaurent une ébauche d'échange avec les citoyens à persuader (interrogations, prise en compte des objections des électeurs comme chez Daniel Gluckstein), tout en se faisant l'écho des débats politiques en cours sur l'insécurité ou la fracture sociale.

Prenant pour objet 200 professions de foi diffusées entre 2002 et 2010 (dont plus de la moitié concernent des élections présidentielles), Françoise Rigat (2010) dissèque leurs modalités d'interpellation de l'électorat. Qu'elles reposent sur des appellatifs au singulier («Madame, Monsieur») ou sur des désignants collectifs ("Français de Métropole et d'Outre-mer»), ces interpellations façonnent des représentations de l'auditoire à convaincre au gré des stratégies politiques mises en place. De même, elles amorcent des relations interpersonnelles tour à tour affectives («Mes chers concitoyens », Nicolas Sarkozy, 2007), identitaires (« Françaises, Français», Marie-George Buffet, 2007) et militantes ("Travailleuses, travailleurs», Arlette Laguiller, 2002) entre le candidat et les électeurs. Par ailleurs, l'évitement des formes d'adresse établit lui aussi un rapport symbolique avec le public, qu'il exprime une volonté de faire de la politique autrement (Alain Madelin en 2002) ou un refus de toute distance (Frédéric Nihous en 2007).

On le voit, les professions de foi présidentielles ont nourri des travaux fructueux, même si ce champ de recherche est encore assez peu investi. La 
dimension rhétorique de ces documents mériterait en effet d'être approfondie, en relation avec leur environnement sociopolitique et la réception des citoyens-électeurs. Sur un autre plan, leur configuration interdiscursive et plus largement la tension entre propagande et communication qui les structure gagneraient à être affinées, notamment par leur confrontation avec d'autres documents produits à l'occasion des campagnes présidentielles. Au demeurant, on peut penser que la continuation des professions de foi lors des présidentielles à venir donnera lieu à des investigations historiographiques sur elles. Bref, elles offrent des perspectives de recherche prometteuses sur la vitalité du débat démocratique en France.

\section{Références}

Alsafar Ali, 2015, L'ethos discursif dans le discours politique électoral français, Paris, Presses académiques francophones.

BAnks David, 2005, "Le packaging de l'inacceptable. Un tract de Le Pen pour l'élection présidentielle de 2002 ", Aspects linguistiques du texte de propagande, D. Banks éd., Paris, L'Harmattan, p. 43-54.

Bon homme Marc, 2004, "Monologisme et dialogisme dans les professions de foi électorales. Le cas des élections présidentielles françaises de 2002 », Structures et discours, A. Auchlin et al. éd., Québec, Nota Bene, p. 349-365.

CAMBon Emmanuelle, 2005, "Le Pen disant "Le Pen" ou la construction du chef charismatique par lui-même», Aspects linguistiques du texte de propagande, D. Banks éd., Paris, L'Harmattan, p. 31-42.

ChetouAn Lamria, 2005, "Comparaison explicite et comparaison implicite dans le discours de propagande électorale», Aspects linguistiques du texte de propagande, D. Banks éd., Paris, L'Harmattan, p. 55-69.

Constantin De Chanay Hugues, 2006, "Pouvoir des images d'avant le pouvoir. De l'ethos dans les portraits des candidats à l'élection présidentielle 2002 en France », Semiotica, no159, p. 151-177.

DÉLOYE Yves, 1999, "Se présenter pour représenter. Enquête sur les professions de foi électorales de 1848 ", La profession politique. XIXe-Xxe siècles, M. Offerlé éd., Paris, Belin, p. 231-254.

GAïтı Brigitte, 1999, "Syndicat des anciens” contre "forces vives” de la nation. Le renouvellement politique de 1958 ", La profession politique. XIXe-Xxe siècles, M. Offerlé éd., Paris, Belin, p. 279-307.

GUARESI Magali, 2014, "Les mots des politiques du genre dans les professions de foi aux élections législatives françaises (1958-2007)», Synergies Italie, nº10, p. 33-48. LÉvÊQUE Sandrine, 2005, "La féminité “dépassée”? Usages et non-usages du genre dans les professions de foi des candidat(e)s parisien(ne)s aux élections législatives de 2002 ", Revue française de science politique, vol.55, n³, p. 501-520.

LOZACHMEUR Ghislaine, 2005, "Les actants et les relations interpersonnelles dans le 
texte de propagande politique : les élections du printemps 2002 », Aspects linguistiques du texte de propagande, D. Banks éd., Paris, L'Harmattan, p. 97-112.

Morin Aurélie, Sourd Cécile, 2007, «Usages et usagers du mot démocratie. Une étude des professions de foi des candidats aux élections législatives et cantonales», Mots. Les langages du politique, n83, « Dire la démocratie aujourd’hui », p. 23-35.

OrIOL Paul, 2000, "Les immigrés aux élections européennes de 1999 », Migration et société, $\mathrm{n}^{0} 12$, p. 29-34.

PAOLETTI Marion, 2005, «Domestiquer la représentation politique. Les professions de foi pour les élections législatives de 2002 ", Mots. Les langages du politique, n 77 , «Proximité », p. 29-39.

PRost Antoine, 1974, Vocabulaire des proclamations électorales de 1881, 1885 et 1889 , Paris, PUF.

RAMPon Jean-Michel, 2006, «Professions de foi et élections présidentielles de 2002. Une approche verbale de la distance entre candidats », Mots. Les langages du politique, n 81, "Suisse, laboratoire politique européen ? », p. 93-108.

RAULet Élodie, 2004, "L'analyse lexicale des discours de candidature», La Communication politique après le tournant de 2002, P. Maarek éd., Paris, L’Harmattan, p. 59-78.

RIGAT Françoise, 2010, “"Mes chers compatriotes”. Stratégies discursives de l'interpellation des électeurs dans les professions de foi », Corela, Hors-série n 8. 
